Brit. J. vener. Dis. (1959), 35, 139.

\title{
AN EXAMINATION OF THE TREPONEMAL WASSERMANN REACTION AND REITER PROTEIN COMPLEMENT-FIXATION TEST*
}

\author{
BY \\ P. J. L. SEQUEIRA \\ Central Serological Laboratory, Manchester (formerly of The Royal Free Hospital, London)
}

Less than one year after the description of the Treponema pallidum by Schaudinn and Hoffman, the first report of the application of the complementfixation reaction of Bordet and Gengou (1901) to the diagnosis of human syphilis was published in Budapest by Detre (1906), exactly 2 weeks after the appearance of the classical paper "A Sero-diagnostic Reaction in Syphilis" by Wassermann, Neisser, and Bruck (1906). These workers used antigens consisting of saline extracts of tissues known to contain large numbers of treponemata, and deemed that the antigens of these treponemata were responsible for the observed specificity of their tests.

Within a year, however, it was found that serviceable antigens for the diagnosis of syphilis could be prepared from normal tissues (Marie and Levaditi, 1907; Landsteiner, Müller, and Poetzl, 1907), and within 4 years antigens derived from alcoholic extracts of heart muscle with added cholesterol were in use (Browning, Cruickshank, and M'Kenzie, 1910; Sachs, 1911), and these, with developments and modifications, have remained the basis of the sero-diagnosis of syphilis.

Since the introduction of the Treponemal Immobilization (TPI) test by Nelson and Mayer (1949), the intense research of the early years of the century has been mirrored by a world-wide return to Wassermann and Detre's original concept, and an increasing number of tests using antigens derived from both virulent and avirulent strains of treponemata have been introduced. These tests detect not only Wassermann antibody (reagin) but other antibodies found in the sera of patients suffering from the treponematoses, and have allowed conclusions to be drawn on the antigenic structure of $T$. pallidum. Table I shows the probable antigenic structure of

* Paper read to M.S.S.V.D. on March 20, 1959. both the Nichols and Reiter strains of treponemata. The Table is constructed to stress their similarity rather than their considerable differences. It is not unlikely that there are other antigens, or that some, for example the protein fraction, are mixtures of antigens. The structure of the Nichols strain was deduced from agglutination studies by Hardy and Nell $(1955,1957)$, and that of the Reiter treponeme by D'Alessandro and Oddo (1948) and D'Alessandro, Oddo, and Dardanoni (1950) both from agglutination studies and by chemical fractionation.

TABLE I

ANTIGENS OF THE TREPONEMATA

\begin{tabular}{|c|c|c|}
\hline $\begin{array}{l}\text { Nichols } \\
\text { Strain }\end{array}$ & Reiter's Strain & $\begin{array}{l}\text { Antibody } \\
\text { detected by }\end{array}$ \\
\hline Lipoid & $\cdots \quad \cdots$ & $\begin{array}{l}\text { STS, ?TWR, } \\
\text { TPA }\end{array}$ \\
\hline Thermolabile & Thermolabile (TL) Protein. . & $\begin{array}{l}\text { TPCF, RCF, } \\
\text { RPCF, ?TPI }\end{array}$ \\
\hline \multirow[t]{2}{*}{ Thermostable } & $\begin{array}{c}\text { Thermostable (TS) Polysac- } \\
\text { charide }\end{array}$ & $\begin{array}{l}\text { RCF, ?TWR } \\
\text { TPA, ?TPI }\end{array}$ \\
\hline & $\begin{array}{l}\text { Organ-specific for brain, } \\
\text { Lipoid }\end{array}$ & \\
\hline
\end{tabular}

The presence of a lipoidal antigen in $T$. pallidum would explain the observed sensitivity of the standard tests for syphilis (STS) in the treponematoses, but does not rule out special circumstances occurring in non-treponemal diseases which result in autoimmunization with tissue lipoids. The postulation of two immunological mechanisms would explain the regular appearance of reagin in the treponematoses and its irregular appearance in diseases known to be associated with biologic false positive (B.F.P.) reactions.

Some information about the distribution of the antibodies to the heat-stable antigens are given by 
D’Alessandro and Oddo (1948), Puccinelli (1952), and Hardy and Nell (1957). The fourth antigen of Reiter's treponeme, which was described by Witebsky (1929), appears to be an immunological curiosity.

Antibodies to the protein fractions appear earlier than immobilizing antibody, but are distinct from reagin.

Table II shows a selection of the tests which are now available for the detection of treponemal disease and the antibodies which may be involved in the reactions. The STS require no comment except that experience of their behaviour is greater than that of any other serologic test, and the observed specificity of about 99.9 per cent. may be approaching the practical limit of specificity obtainable with any immunological reaction. The next five tests use antigens derived from Nichols strain of $T$. pallidum. This organism was isolated from the cerebrospinal fluid of a patient with relapsing neuro-syphilis by Nichols and Hough (1913). In spite of having been maintained in animals for over 40 years, it is able to cause clinical syphilis in man. According to Turner and Hollander (1957), laboratory infections most commonly result from accidents occurring during the inoculation of animals, and therefore apply to a greater or lesser extent to all these tests, even those using a non-living antigen. The technical difficulties of the TPI test are well known; they apply, however, more to the starting of the test in a new centre than to the week-to-week performance of the test, and with experience a reasonably regular service can be maintained. Further considerable experience of the test has been gained and it has

TABLE II

SEROLOGICAL TESTS FOR SYPHILIS

\begin{tabular}{|c|c|}
\hline Test & $\begin{array}{l}\text { Probably } \\
\text { Detects }\end{array}$ \\
\hline Standard Tests for Syphilis (STS) & Reagin \\
\hline Treponemal Immobilization (TPI) Test. . & Immobilisin \\
\hline Treponemal Immune Adherence (TPIA) Test .. & ?Immobilisin \\
\hline Treponemal Agglutination (TPA) Test.. & $\begin{array}{l}\text { Reagin } \\
\text { ?Immobilisin }\end{array}$ \\
\hline Treponemal Complement-Fixation (TPCF) Test & $\begin{array}{l}\text { ?TL Antibody } \\
\text { ?Immobilisin }\end{array}$ \\
\hline Treponemal Wassermann Reaction (TWR) $\quad$.. & $\begin{array}{l}\text { ?Reagin } \\
\text { ?Immobilisin } \\
\text { Another Factor }\end{array}$ \\
\hline Reiter Complement-Fixation (RCF) Test & $\begin{array}{l}\text { TL Antibody } \\
\text { TS Antibody }\end{array}$ \\
\hline 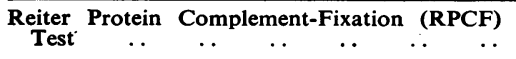 & TL Antibody \\
\hline
\end{tabular}

proved generally acceptable to the clinician. The TPA and TPIA tests, while appearing simple procedures have in the author's experience hidden difficulties, especially in the variation between antigen batches and in the reproducibility of the tests. These tests have, however, provided valuable information on the phenomenon of immune adherence (Nelson, 1953), and on the antigenic structure of $T$. pallidum (Hardy and Nell, 1955, 1957). All these treponemal tests are read with the microscope, and the author suggests that, from among them, the test of choice is the TPI test, and that its reliability and the experience gained over 9 years outweigh its technical problems.

The remainder are complement-fixation tests. The TPCF test appears most promising from published reports (Magnuson and Portnoy, 1956; Portnoy and Magnuson, 1955), and achieves very close agreement with the TPI test, except in early syphilis when it is more sensitive. The antigen is, however, laborious to produce and, though commercially available in the United States, costs about $\$ 3$ per test dose.

The antigen of the TWR is relatively easy to produce, the technique of the test is straightforward though carried out in small volumes and requires only standard serological equipment.

The remaining tests use antigens derived from cultivable, avirulent strains of treponemata, and in practice from Reiter's strain and its variants. This strain was isolated by Wassermann and Ficker (1922) and, together with certain other strains, was passed on to Reiter for further study. The details of the isolation of this organism do not appear in the original literature, though Ruge (1956) stated that it was isolated from a patient with primary syphilis. Whatever its origin, it is now distinct from the causative agent of syphilis in that it is avirulent for man and animals, multiplies in relatively simple media, and can survive for long periods without subculture. Commercially prepared suspensions of this organism for use as an antigen in the diagnosis of syphilis were available before 1939 and were widely used in Germany and elsewhere, but they were not universally accepted, possibly because of crossreactions with the standard Wassermann reaction. The use of these suspensions has been reviewed by Gaehtgens (1929, 1937). In the RCF test, these cross-reactions do not occur, as the antigen is a variant of Reiter's treponeme isolated by D'Alessandro and is without a serologically active lipoid antigen. Good results have been reported by numerous workers, including Wilkinson (1957), but it appears that the last test on the list is superior to it. The antigen is a protein fraction of the Reiter treponeme, the test being referred to as the Reiter 
Protein Complement-Fixation (RPCF) test, though the antigen corresponds to the TL (thermolabile) antigen of the earlier Italian literature. Reports on this test include those of De Bruijn and Bekker (1957), Rein, Kelcec, D'Alessandro, and De Bruijn, (1957), and Foster, Nicol, and Stone (1958), who found the test both sensitive and specific.

From this incomplete review of the treponemal tests for syphilis, it appears that from among them, only three (the TWR, the RCF test, and the RPCF test) are technically suitable for the routine serological laboratory.

The comparison of serological tests detecting different antibodies which occur together in one disease differs radically from the comparison of two tests for the same type of antibody. For example, if the behaviour of two STS and the TPI test are compared in various stages of syphilis, discrepancies between the STS results will be determined primarily by their relative sensitivities, while discrepancies between the STS and TPI test will be determined primarily by the state of the disease. Thus, in primary syphilis, the STS are frequently positive and the TPI test negative, while in late syphilis, this pattern of results is so rare that it may be justifiable to reconsider the diagnosis, even in remotely treated patients. The relative sensitivity of some of the tests considered is shown in the Figure.

If, however, the TPI test is replaced by another treponemal test which detects reagin in addition to a second antibody, this test will be positive on some occasions because of the reagin alone and will therefore be unable to distinguish between some biologic false positive reactions and syphilis. The TPA test is of this type, reagin causing rapid agglutination of the antigen, while a second antibody requires incubation overnight to produce a detectable reaction. In practice, it is possible to distinguish between the two reactions by removing the reagin by adsorption with STS antigen. The position is further complicated by the finding that a proportion of STS-negative sera contain an aggultinin for TPA antigen which can be removed by adsorption with STS antigen, and is therefore a type of reagin. Among the reagins detected by the STS in biologic false positive reactors, only those of about half the patients

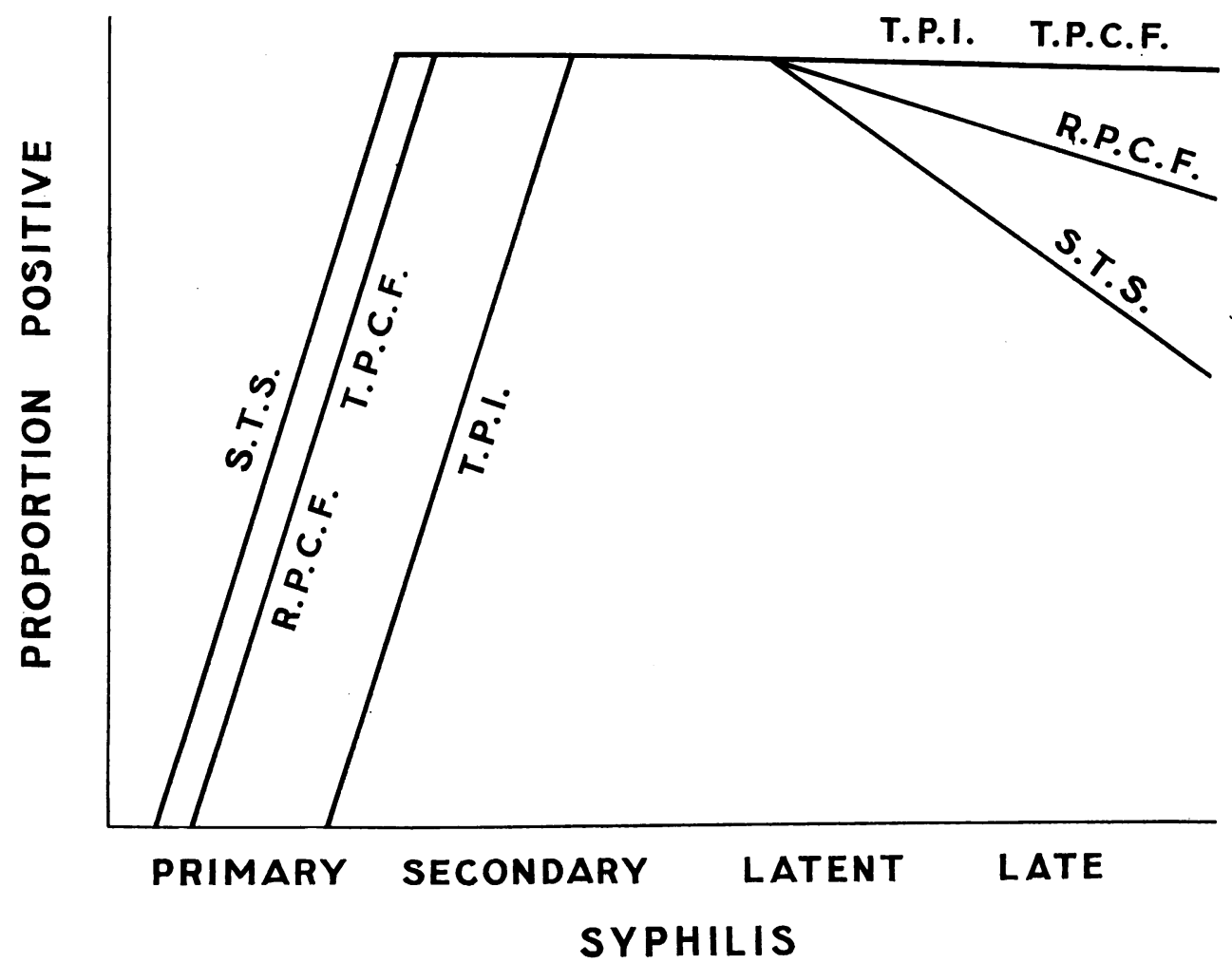

FIGIRE.-Sensitivities of certain tests at different stages of syphilis. In early syphilis, the STS are more sensitive than the TPI test, as are also the RPCF and TPCF tests. In late syphilis, the TPI and TPCF tests are more sensitive than the STS, and the RPCF test occupies an intermediate position. 
agglutinate TPA antigen. Thus, while cross-reactions due to a single type of antibody (reagin) may occur between the STS and TPA test, discrepancies may be found in which either test is positive. The possibility of the occurrence of analogous cross-reactions must be considered when the behaviour of other tests is assessed.

It would also be unwise to assume that conditions associated with biologic false positive reactions with the STS will be those which are associated with analogous reactions (if these occur) in the treponemal tests, unless cross-reactions involving the reagins are included. The treponemal tests may have as high a specificity among biologic false positive (STS) reactors as with normal individuals, but may have a lower specificity than the STS in another group of conditions, as yet undefined.

\section{Methods}

The Wassermann reaction was carried out by the Whitechapel technique (Price, 1950) using standard antigen at its optimal titre, and with cardiolipin antigen (Price and Wilkinson, 1952). Price's precipitation reaction (PPR) and the treponemal Wassermann reaction (TWR) were carried out as originally described (Price, 1948; Price and Whelan, 1956).

The RPCF test was carried out by a modified Whitechapel WR technique. Preliminary experiments with this method showed that, using the normal amount of complement, the test was of rather low sensitivity. It was therefore carried out with the complement dilution in the diagnostic row equal to the titration reading and not, as is usual, to one and a quarter times that amount. In practice, the test consisted of an additional row in the Wassermann reaction and, since the antigen is not anticomplementary, the dilution of complement used was frequently the same as in the serum controls. The antigen was obtained commercially.*

The treponemal immobilization (TPI) test was carried out as described by Nelson and Mayer (1949) with the following modifications:

The amounts of serum ultrafiltrate and sodium thioglycollate in the medium were doubled and trebled respectively. Streptomycin was added to the test mixture to a final concentration of $150-200 \mu \mathrm{g} . / \mathrm{ml}$. The tests were incubated in a mixture of hydrogen 95 per cent., carbon dioxide 5 per cent. in a McIntosh and Fildes jar which was evacuated and refilled with gas mixture once only. The sera used were not separated aseptically, but selected from those used for the STS. All sera were treated with penicillinase before testing. The volumes used in the test were $0.033 \mathrm{ml}$. patient's serum, $0 \cdot 1 \mathrm{ml}$. guinea-pig serum, $0.2 \mathrm{ml}$. treponeme suspension (total volume $0.333 \mathrm{ml}$.).

\footnotetext{
* Organon Laboratories.
}

The tests were read using a dry dark-ground condenser and special 4-mm. objective† with a 48-watt high intensity lamp.

\section{Material}

The material presented, consisting of three distinct series, is summarized in Table III. In each series, all sera were examined with a battery of STS, consisting of the Wassermann reaction using both standard and cardiolipin antigens; and the PPR. The sera were also subjected to the Kahn test, but these results are not analysed in this report.

TABLE III

MATERIAL

\begin{tabular}{|c|c|c|c|c|c|c|c|}
\hline Serie & & Test & & Clinic & G.H. & Problem & A.N. \\
\hline \multirow{2}{*}{ TWR } & \multirow{2}{*}{. } & TWR & . & 471 & 649 & 57 & 433 \\
\hline & & TPI & . & 128 & 122 & 53 & 60 \\
\hline \multirow{3}{*}{ RPCF } & \multirow{3}{*}{. } & RPCF & . & 1,004 & 1,154 & 479 & 966 \\
\hline & & TPI & $\ldots$ & 88 & 129 & 474 & 17 \\
\hline & & TWR & & 87 & 120 & 444 & 15 \\
\hline \multirow{3}{*}{$\begin{array}{l}\text { Blood } \\
\text { Donors }\end{array}$} & \multirow{3}{*}{$\cdots$} & RPCF & . & & 899 & & \\
\hline & & TPI & $\ldots$ & & 898 & & \\
\hline & & TWR & $\ldots$ & & 763 & & \\
\hline
\end{tabular}

In the TWR series, that test was carried out on all sera (when technically possible) and, unless the result was known for the patient in question, the TPI test was carried out as far as was practicable on all sera giving a positive reaction with any test. In the RPCF test series, all sera were examined with the STS battery and the RPCF test, and the TWR and TPI test were used in confirmation. In both series, the TPI test was also carried out on a number of STS-negative sera when a clinical diagnosis of symptomatic syphilis seemed possible. The Table shows the number of sera examined by the various tests, classified as V.D. clinic patients (Clinic), and general hospital (G.H.) and antenatal clinic (A.N.) patients. These groups are unselected, and include only patients from hospitals for which the Marlborough Laboratory, Royal Free Hospital, provides a routine serology service. Those marked "Problem" are selected sera sent from elsewhere, usually because of the finding of positive or inconclusive STS. This group differs very significantly from the others in that the vast majority of STS-negative patients are excluded.

The blood donor series comprises sera from unselected blood donors which were kindly sent to me by Dr. James of the N.W. Metropolitan Blood Transfusion Centre. This series consists virtually exclusively of healthy European adults, the STS and RPCF test were carried out on 899, the TPI test on 898, and the TWR on the last 763 of the series.

† W. Watson \& Sons Ltd., High Holborn, London, W.C.1. 
Results and Discussion

The blood donor series is presented as a group of apparently healthy persons in whom the incidence of syphilis may be assumed to be low. This assumption is supported by the low incidence of positive reactions (Table IV).

TABLE IV

RESULTS IN BLOOD DONORS

\begin{tabular}{|c|c|c|c|c|}
\hline \multicolumn{4}{|c|}{ Test Results } & \multirow{2}{*}{$\begin{array}{l}\text { No. of } \\
\text { Cases }\end{array}$} \\
\hline STS & RPCF & TWR & TPI & \\
\hline+ & + & + & + & 1 \\
\hline- & + & + & + & 1 \\
\hline- & - & + & + & 3 \\
\hline- & - & - & \pm & 1 \\
\hline+ CWR & - & - & - & 6 \\
\hline+ PPR & - & + & - & 1 \\
\hline- & - & + & - & 12 \\
\hline- & - & + & 0 & 1 \\
\hline
\end{tabular}

The PPR, Kahn, and Cardiolipin WR (CWR) were positive in one donor, and as the TPI and RPCF tests and the TWR were also positive, it is reasonable to consider this to be a case of syphilis. In another donor, the three treponemal tests were positive and the reagin tests negative. The TPI test and TWR were positive in three more cases and the TPI test weakly reactive in one. There were also six positive reactions with the CWR, which is oversensitive for use as a routine sero-diagnostic test, and twelve unsupported positive reactions with the TWR. Table V shows the specificity observed throughout the series with individual tests. Overall, the TWR has an incidence of possible false positive reactions of not more than $2 \cdot 1$ per cent., as compared with 1 per cent. with the CWR, 0.7 per cent. with the TPI test, and 0.2 per cent. with the RPCF test. If the STS,

TABLE V SPECIFICITY

\begin{tabular}{|c|c|c|c|c|c|c|}
\hline \multirow{2}{*}{\multicolumn{3}{|c|}{ Test }} & \multicolumn{2}{|c|}{ Total Positive } & \multicolumn{2}{|c|}{ Positive Alone } \\
\hline & & & No. & Per cent. & No. & Per cent. \\
\hline WR & $\cdots$ & $\cdots$ & 0 & 0 & 0 & 0 \\
\hline CWR & $\cdots$ & $\cdots$ & 9 & $1 \cdot 0$ & 6 & 0.7 \\
\hline PPR & $\cdots$ & $\cdots$ & 2 & $0 \cdot 2$ & 0 & 0 \\
\hline KAHN & . & $\cdots$ & 1 & $0 \cdot 1$ & 0 & 0 \\
\hline RPCF & $\cdots$ & $\cdots$ & 2 & 0.2 & 0 & 0 \\
\hline TPI & $\cdots$ & $\cdots$ & 6 & $0 \cdot 7$ & 1 & $0 \cdot 1$ \\
\hline TWR & $\ldots$ & . & 18 & $2 \cdot 1$ & 12 & $1 \cdot 6$ \\
\hline
\end{tabular}

TWR, and RPCF and TPI tests are all considered as detecting a different antibody, and the finding of positive reactions with two or more types of test is considered as evidence of past treponemal infection, the rate of false positive reactions with all tests except the TWR and CWR falls to vanishing point, and brings the incidence of syphilis in the series to about 0.5 per cent. In such a series, the finding of an occasional positive TPI test would not be unusual.

These results indicate that the RPCF test is of satisfactory specificity as is also the TPI test within the limits of the material. The TWR, on the other hand, gives over 1.5 per cent. positive reactions in STS-negative, TPI test-negative donors.

Table VI compares the TPI test and TWR results in the TWR series, but includes the "Problem" group from the RPCF test series as the selection of these groups in each series is the same. There were very few doubtful reactions with either test, and these have been included with the positives to simplify the Tables. "O" in the TPI test column indicates that this test was not carried out. Among the "Clinic" patients, the TWR-positive, TPI " $O$ " group included virtually all the known cases of syphilis and this was also the case with the "G.H" patients who showed this pattern of results. The status of the nine "A.N." patients is not known.

TABLE VI

TWR SERIES (INCLUDING PROBLEM SERA FROM RPCF TEST SERIES)

\begin{tabular}{|c|c|c|c|c|c|c|c|c|c|}
\hline \multirow{2}{*}{$\frac{\text { Series . . }}{\text { TWR Result }}$} & \multirow{2}{*}{$\begin{array}{l}\cdots \\
\cdots\end{array}$} & \multicolumn{2}{|c|}{ Clinic } & \multicolumn{2}{|c|}{ G.H. } & \multicolumn{2}{|c|}{ Problem } & \multicolumn{2}{|c|}{ A.N. } \\
\hline & & + & - & + & - & + & - & + & - \\
\hline \multirow{3}{*}{$\begin{array}{l}\text { TPI } \\
\text { Result }\end{array}$} & + & 54 & 6 & 21 & 11 & 322 & 19 & 10 & 0 \\
\hline & - & 26 & 38 & 36 & 61 & 31 & 122 & 36 & 13 \\
\hline & 0 & 44 & 301 & 26 & 499 & 1 & 2 & 9 & 373 \\
\hline
\end{tabular}

In each section of Table VI, except the "Problem" sera, there is an excess of TWR-positive TPInegative results, amounting in the "Clinic" patients to a quarter of the positive TPI results, and in the "A.N." patients to almost certainly more than twice and possibly as much as four times the number of positive results due to syphilis. In the "Problem" group, the position superficially appears to be very different, and the agreement between the TWR and TPI test to be good. The explanation lies in the high incidence of treponemal disease in this group, due to the elimination of the majority of the STSnegative patients inherent in selection of these 
patients. The effect of the removal of the bulk of patients with treponematoses is shown in Table VII, from which patients with positive TPI tests are excluded. In only two of the "Problem" group were both the WR and the PPR positive, while in two more the WR was positive alone. The next section of Table VII concerns patients in whom neither the routine WR nor the PPR was positive. Among sera in which the CWR was positive, the number in which the TWR was positive or negative is compared. Finally, the patients in whom the TWR was positive and the TPI test and the STS (including the CWR) were negative are compared with those in whom no test carried out was positive; this amounted to $4 \cdot 6,4 \cdot 6$, and $7 \cdot 1$ per cent. of the Clinic, G.H., and A.N. patients respectively, and to 23 per cent. of the "Problem" group.

TABLE VII

STS RESULTS IN TWR-POSITIVE AND TPI-NEGATIVE CASES

\begin{tabular}{|c|c|c|c|c|c|}
\hline Series & .. & Clinic & G.H. & $\begin{array}{c}\text { Prob- } \\
\text { lem }\end{array}$ & A.N. \\
\hline $\mathbf{W R}+\mathbf{P P R}+$ & $\ldots$ & 0 & 0 & 2 & 0 \\
\hline WR + PPR - & .. & 0 & $\mathbf{0}$ & 2 & $\mathbf{0}$ \\
\hline \multirow{4}{*}{ WR - PPR - } & CWR + TWR + & 6 & 6 & 6 & 4 \\
\hline & CWR + TWR - & 5 & 0 & 28 & 9 \\
\hline & CWR - TWR + & 20 & 30 & 25 & 32 \\
\hline & $\begin{array}{l}\text { CWR - TWR - } \\
\text { TPI - or } 0 \quad . .\end{array}$ & 415 & 620 & 85 & 421 \\
\hline $\begin{array}{c}\text { Per cent. } T \\
\text { Tests }\end{array}$ & $\begin{array}{ccc}\mathbf{R}+ & \text { and } & \text { Other } \\
. . & \ldots & \ldots\end{array}$ & $4 \cdot 6$ & $4 \cdot 6$ & 23 & $7 \cdot 1$ \\
\hline
\end{tabular}

Of these results, those of the A.N. patients require special consideration. None of the $7 \cdot 1$ per cent. positives was detected by the reagin tests (including the CWR), or by the TPI test. In the last 6 years, among the patients attending the ante-natal clinics of the Royal Free Hospital Group, no patient was delivered of a child with congenital syphilis in whom ante-natal testing with this battery of STS was negative. Further, there appears to be no reason to believe that these ante-natal patients differ very significantly from the remainder of those tested during the 6-years period. It is therefore suggested that, even if any of these unsupported positive TWR results represent cases of treponemal infection, they may safely be considered as bacteriologically cured; therefore, on a basis of utility even if not of specificity in its narrowest sense, the TWR would not appear of value in the control of the treponematoses.

The RPCF test has already been shown to be sufficiently specific when examining normal persons. It remains to be decided whether it has a suitable level of sensitivity for use as a routine or confirmatory test. Table VIII compares the TPI and RPCF tests in Clinic, G.H., A.N., and "Problem" groups. In each group, the same pattern is repeated, modified by the proportion of normal sera examined and the number of TPI tests carried out. While discrepancies occur in both directions, the TPI test appears the more sensitive. The proportion of RPCF to TPIpositive reactions is similar in each group with a slight preponderance in the Royal Free Hospital patients. As the results in each group are similar, the material is presented as a single series.

TABLE VIII

RPCF TEST SERIES

\begin{tabular}{|c|c|c|c|c|c|c|c|c|c|}
\hline \multirow{2}{*}{\multicolumn{2}{|c|}{$\frac{\text { Series }}{\text { RPCF Result .. }}$}} & \multicolumn{2}{|c|}{ Clinic } & \multicolumn{2}{|c|}{ G.H. } & \multicolumn{2}{|c|}{ Problem } & \multicolumn{2}{|c|}{ A.N. } \\
\hline & & + & - & + & - & + & - & + & - \\
\hline \multirow{3}{*}{$\begin{array}{l}\text { TPI } \\
\text { Result }\end{array}$} & + & 47 & 11 & 35 & 17 & 230 & 97 & 4 & 3 \\
\hline & - & 5 & 25 & 7 & 70 & 13 & 134 & 1 & 5 \\
\hline & 0 & 0 & 916 & 0 & 1,025 & 2 & 3 & 0 & 953 \\
\hline
\end{tabular}

Table IX (opposite) compares the sensitivity of five tests in patients with primary or secondary syphilis. The Table includes patients in whom the date and amount of treatment are known to the author, but four patients who received less than one mega unit penicillin for co-existent gonorrhoea are excluded. The patients are classified on the basis of treatment. "Nil" indicates untreated patients, "minus one year" and "plus one year" indicate that treatment was started less or more than one year before the tests in question. Among the patients with early syphilis, the only tests to detect all nine untreated patients were the CWR and the RPCF test. In the fifteen patients who had been treated less than one year previously, a greater proportion gave negative results with each test than among the untreated patients. While this may be partly due to the selection of the patients, a larger proportion of the WR, PPR, and RPCF tests are negative than the TPI test and CWR.

Table IX also compares the sensitivity of the tests in latent and late symptomatic syphilis. In each group approximately two-thirds are patients with latent syphilis. Here again, only the TPI test and CWR detected all untreated infections, while the RPCF test was negative in two cases of latent syphilis. These results do not exclude the possibility of some cases not being detected by any test, but the finding of an additional nine among the 42 untreated patients represents a sensitivity considerably higher 
TABLE IX

RESULTS IN CASES OF SYPHILIS SHOWING TREATMENT RECEIVED

\begin{tabular}{|c|c|c|c|c|c|c|c|c|}
\hline \multirow{2}{*}{$\frac{\text { Syphilis .. }}{\text { Treatment }}$} & \multirow{2}{*}{$\begin{array}{ll}\cdots & \cdots \\
\ldots & . \\
\end{array}$} & \multirow{2}{*}{$\begin{array}{l}\cdots \\
\ldots\end{array}$} & \multicolumn{3}{|c|}{ Early } & \multicolumn{3}{|c|}{ Late and Latent } \\
\hline & & & Nil & -1 year & +1 year & Nil & -1 year & +1 year \\
\hline \multirow{10}{*}{ Test Results } & \multirow{2}{*}{ WR $\quad}$. & + & 6 & 6 & 0 & 33 & 13 & 17 \\
\hline & & - & 3 & 9 & 3 & 9 & 3 & 12 \\
\hline & \multirow{2}{*}{ CWR .. } & + & 9 & 12 & 0 & 42 & 16 & 28 \\
\hline & & - & 0 & 3 & 3 & 0 & 0 & 1 \\
\hline & \multirow{2}{*}{ PPR } & + & 6 & 3 & 0 & 25 & 9 & 17 \\
\hline & & - & 3 & 12 & 3 & 17 & 7 & 12 \\
\hline & \multirow{2}{*}{ TPI $\quad}$. & + & 8 & 13 & 2 & 42 & 16 & 28 \\
\hline & & - & 1 & 2 & 1 & 0 & 0 & 1 \\
\hline & \multirow{2}{*}{ RPCF . . } & + & 9 & 6 & 0 & 40 & 10 & 23 \\
\hline & & - & 0 & 9 & 3 & 2 & 6 & 6 \\
\hline Totals & $\cdots$ & . & 9 & 15 & 3 & 42 & 16 & 29 \\
\hline
\end{tabular}

than that of the routine WR. As the time after treatment increased, a larger number of the results of each test was negative, though clearly not a significantly larger number of results of the CWR and TPI test. This proportion of negative results was greatest with the WR and PPR, and the RPCF test occupied an intermediate position between the routine STS and the TPI test and CWR. Thus, in the material presented, the RPCF test, in addition to having high specificity, had a sensitivity greater than that of the routine STS but less than that of the TPI test, this being most marked in patients with late and treated syphilis. The high sensitivity of the CWR is also noteworthy.

The whole series included 89 patients in whom the diagnosis of syphilis was established on clinical grounds. Of the ten patients with a negative TPI test, were two with untreated primary syphilis, four with treated early syphilis, two with treated congenital syphilis, and one each with cardiovascular and asymptomatic neurosyphilis, both of whom had received treatment, the former, more than 6 years previously. The results obtained in these 89 patients are summarized in Table X (overleaf).

The RPCF test was negative in nine of the TPInegative patients, the exception being a patient with primary syphilis, and in sixteen of the TPI-positive patients. In nine of these sixteen patients the treatment status was unknown to the author: two patients had latent syphilis, three had cardiovascular syphilis, and three had neurosyphilis; the ninth was over 60 years of age and had congenital syphilis. The remaining seven RPCF-negative patients had all received treatment; two had been treated for secondary syphilis and one for neurosyphilis about one year before the tests, and the others (three with neurosyphilis and one with a congenital infection) had all been treated over 6 years previously.

In addition to the patients so far considered, there were 103 whose treatment status was unknown but in whom the diagnosis of latent syphilis was based on the finding of positive STS and TPI tests. Three of these were possibly cases of late symptomatic syphilis. This group contained eleven patients in whom the RPCF test was negative. This proportion is intermediate between that in the untreated and treated groups of patients with late and latent syphilis. This is the expected finding, as 94 of these sera had been sent in for examination as presenting a problem in diagnosis. In seventeen patients, the PPR was negative, and in six of these the routine WR was negative also. In all patients of this group, however, the CWR was positive.

In the whole series, there were 26 patients who had a negative TPI test and positive RPCF test. These included one patient with a history of previous yaws and the patient with untreated primary syphilis already mentioned. Of these 26 patients, only two had strongly positive STS, and in one of these, the RPCF was weakly reactive but had been read as negative on a previous specimen which was not entirely satisfactory from a technical point of view as the serum was slightly anti-complementary. This patient had been diagnosed as suffering from latent syphilis about 20 years before and had been fully treated and followed up. No supporting evidence of syphilis was ever found. In the two specimens examined, the PPR was positive at a dilution of 1 in 8 and 1 in 16, and the TPI test was negative. During the previous year this woman developed 
TABLE X

RESULTS IN CASES OF SYPHILIS, CLINICALLY CONFIRMED

\begin{tabular}{|c|c|c|c|c|c|c|c|c|c|}
\hline \multicolumn{4}{|c|}{ Test Results } & \multicolumn{6}{|c|}{ Number of Patients with Syphilis } \\
\hline TPI & RPCF & STS & CWR & Early & $\begin{array}{c}\text { Cardiovascular } \\
\text { System }\end{array}$ & $\begin{array}{l}\text { Central } \\
\text { Nervous } \\
\text { System }\end{array}$ & $\begin{array}{c}\text { Other } \\
\text { Late and } \\
\text { Latent }\end{array}$ & Congenital & Total \\
\hline \multirow{5}{*}{+} & \multirow{5}{*}{+} & + & & 8 & 15 & 10 & 5 & 2 & 40 \\
\hline & & \pm & & 1 & 4 & 1 & 3 & 1 & 10 \\
\hline & & - & + & 0 & 3 & 3 & 1 & 0 & 7 \\
\hline & & - & - & 0 & 1 & 3 & 0 & 0 & 4 \\
\hline & & Total & .. & 9 & 23 & 17 & 9 & 3 & 61 \\
\hline \multirow{5}{*}{+} & \multirow{5}{*}{-} & + & & 0 & 0 & 1 & 0 & 1 & 2 \\
\hline & & \pm & & 1 & 2 & 0 & 0 & 1 & 4 \\
\hline & & - & + & 1 & 1 & 2 & 1 & 0 & 5 \\
\hline & & - & - & 1 & 0 & 4 & 1 & 1 & 7 \\
\hline & & Total & $\ldots$ & 3 & 3 & 7 & 2 & 3 & 18 \\
\hline- & + & - & + & 1 & 0 & 0 & 0 & 0 & 1 \\
\hline \multirow{5}{*}{-} & \multirow{5}{*}{-} & + & & 0 & 0 & 0 & 0 & 1 & 1 \\
\hline & & \pm & & 0 & 1 & 0 & 0 & 0 & 1 \\
\hline & & - & + & 3 & 0 & 0 & 0 & 0 & 3 \\
\hline & & - & - & 2 & 0 & 0 & 1 & 1 & 4 \\
\hline & & Total & $\cdots$ & 5 & 1 & 0 & 1 & 2 & 9 \\
\hline \multicolumn{2}{|c|}{ Grand Total ... } & & $\cdots$ & 18 & 27 & 24 & 12 & 8 & 89 \\
\hline
\end{tabular}

STS $+=$ WR and PPR positive or one positive and one weakly reactive. STS $-=$ WR and PPR negative. STS $\pm=$ all other results.

various symptoms and when last heard of was being investigated as a possible case of systemic lupus erythematosus, though no L.E. cells had been found and the plasma proteins were normal. It would be difficult on the evidence available to-day to decide whether this patient had syphilis 20 years ago or had shown a chronic biologic false positive reaction. It is suggested that, whatever the correct diagnosis was initially, she does not now have bacteriological syphilis, even if it is held that her serum tests are evidence of serologic syphilis.

In a further eight patients, of the TPI-negative RPCF-positive group, the CWR was positive, and in four one or both of the routine STS.

If the absence of definite clinical evidence and a negative TPI test are considered to exclude the diagnosis of syphilis, among the 4,502 sera examined with the RPCF test and in spite of the inclusion of a considerable proportion of problem cases, an unexplained positive was only found in 24 or 25 patients, in the majority of whom clinical information was totally lacking. Thus the incidence of false positive reactions over the whole series is not greater than 0.55 per cent. and is almost certainly lower.

On the author's experience of the RPCF test and the results presented, the finding of a positive STS and a positive RPCF test (including weakly-positive reactions confirmed by re-testing on the same and on a second specimen), would appear to be conclusive evidence of past or present treponemal infection. The finding of positive STS and a negative RPCF test is unusual in untreated syphilis, while the finding of a positive RPCF test and negative STS is not rare in either untreated or treated patients. It is suggested that, in these not inconsiderable groups, the TPI test remains irreplaceable. The finding of a negative TPI test (if early syphilis can be excluded) appears a sound basis for the exclusion of a diagnosis of bacteriological syphilis. This supposition is supported by the experience at the Royal Free Hospital, where for over the last 5 years patients (including expectant mothers) with positive STS and negative TPI tests have not been diagnosed as or treated for syphilis. In no case has this practice appeared anything but beneficial to the patient. 


\section{Conclusions}

With the STS, TPI, and RPCF tests, the detection of three distinct antibodies is possible in syphilis. It is suggested that the ideal combination of tests for the diagnosis of the treponematoses is the RPCF test and two tests for reagin, one of standard and one of high sensitivity, with the TPI test as a confirmatory test.

In the combination of a reagin test and the RPCF test, the occurrence of a positive reaction in both should have a specificity of over 99.99 per cent., that is one false positive in over 10,000 patients, and a sensitivity for bacteriological syphilis considerably higher than that of the STS of acceptable specificity. Discrepant results should be checked with the TPI test, which remains the final standard and is the only test of suitable specificity to distinguish between biologic false positive reactions and certain cases of syphilis. This test system would provide the clinician with an immediate, reliable serologic diagnosis in most of the cases which now cause difficulty; those patients in whom there was delay would comprise the biologic false positive reactors, some with treated syphilis, and a small proportion with active infections.

\section{Summary}

The treponemal Wassermann reaction (TWR) and the Reiter protein complement-fixation test (RPCF test) were examined and their results compared with the clinical findings and the TPI test. The TWR was found to be of an unsatisfactory degree of specificity for use as a routine or confirmatory test. The specificity and sensitivity of the RPCF test were found to be higher than those of the STS.

It is suggested that the ideal combination of tests for the diagnosis of the treponematoses is the RPCF test and two tests for reagin, one of normal and one of high sensitivity, and that discrepancies between the reagin tests and the RPCF test should be submitted to the TPI test.

Thanks are due to the Board of Governors of the Royal Free Hospital for facilities to carry out this work, and especially to my technicians, Mr. A. E. Eldridge and Mrs. Doreen Birch for their unstinted help, and also to the many clinicians and pathologists who have contributed the material used in this study.

\section{REFERENCES}

Bordet, J., and Gengou, O. (1901). Ann. Inst. Pasteur, 15, 289. Browning, C. H., Cruickshank, J., and M'Kenzie, I. (1910). J. Path. Bact., 14, 484.

D'Allessandro, G., and Oddo, F. (1948). Riv. Ist. sieroter. ital., 23, 119 D. (1950). J. vener. Dis. Inform., 31, 314. Detre, L. (1906). Wien. klin. Wschr., 19, 619.

De Bruijn, J. G., and Bekker, J. H. (1957). Ned. T. Geneesk., 101, 1615 Foster, W. D., Nicol, C. S., and Stone, A. H. (1958). Brit. J. vener. Dis., 34, 196.

Gaehtgens, W. (1929). Z. Immun.-Forsch. (Orig.), 63, 398

(1937). Arch. Derm. Syph. (Berl.), 176, 42.

Hardy, P. H., and Nell, E. E. (1955). J. exp. Med., 101, 367.

- (1957). Amer. J. Hyg., 66, 160

Landsteiner, K., Müller, R., and Poetzl, O. (1907). Wien. klin. Wschr., 20. 514 .

Magnuson, H. J., and Portnoy, J. (1956). Amer. J. Publ. Hlth, 46,190.

Marie, A., and Levaditi, C. (1907). Ann. Inst. Pasteur, 21, 138.

Nelson, R. A. (1953). Science, 118, 733 .

- and Diesendruck, J. A. (1951). J. Immunol., 66, 667.

and Mayer, M. M. (1949). J. exp. Med., 89, 369.

Nichols, H. J., and Hough, W. H. (19i3). J. Amer. med. Ass., 60, 108

Portnoy, J., and Magnuson, H. J. (1955). J. Immunol., 75, 348.

Price, I. N. Orpwood (1948). J. clin. Path., 1, 91.

(1950). Brit. J. vener. Dis., 26, 172.

(1958). Ibid., 34, 91 .

and Whelan, M. J. (1957). Ibid., 33, 18.

- and Wilkinson, A. E. (1952). Ibid., 28, 16.

Puccinelli (1952). Ibid, 28, 184.

Rein, C. R., Kelcec, M. T., D'Alessandro, G., and De Bruijn, J. G. (1957). J. invest. Derm., 28, 459.

Ruge, H. G.S. (1956), Brit. J. vener. Dis., 32, 242

Sachs, H. (1911). Berl. klin. Wschr., 48, 2066

Turner, T. B. and Hollander, D. H. (1957). "Biology of the Treponematoses". WHO Monograph Series No. 35. W.H.O., Geneva.

Wassermann, A. von, and Ficker, M. (1922). Klin. Wschr., 1, 1101.

- Neisser, A., and Vruck, C. (1906). Dtsch. med. Wschr., 32, 745.

Wilkinson, A. E.' (1957). Brit. J. vener. Dis., 33, 25.

Witebsky, E. (1929). Z. Immun.-Forsch., 62, 35.

\section{DISCUSSION}

The President, Dr. R. M. WARREN (Southampton) thanked the speakers for their excellent papers. Anything leading to the more accurate diagnosis of disease would be universally welcomed and, for this reason, these contributions were particularly timely.

The point that occurred to him was that the persistence of a positive reaction to the RPCF test after treatment might lead to difficulties in assessing the adequacy of treatment.
DR. T. E. Osmond (London) asked for how long the RPCF test would remain positive after the adequate treatment of primary, secondary, and late syphilis?

Dr. Sequeira said he could not answer this question as the time for sero-reversal appeared to vary very much from case to case and was not related to that of the reagin tests.

DR. W. V. MACFARLANE (Newcastle-on-Tyne) 